\title{
Erratum to: Supply-based optimal scheduling of oil product pipelines
}

\author{
Hao-Ran Zhang ${ }^{1} \cdot$ Yong-Tu Liang $^{1} \cdot$ Qiao Xiao $^{2} \cdot$ Meng-Yu Wu$^{1} \cdot$ Qi Shao $^{1}$
}

Published online: 23 April 2016

(c) The Author(s) 2016. This article is published with open access at Springerlink.com

Erratum to: Pet. Sci.

\section{DOI 10.1007/S12182-016-0081-x}

Unfortunately, in the original published article Fig. 4 was not correct. The correct Fig. 4 is given below.
Open Access This article is distributed under the terms of the Creative Commons Attribution 4.0 International License (http:// creativecommons.org/licenses/by/4.0/), which permits unrestricted use, distribution, and reproduction in any medium, provided you give appropriate credit to the original author(s) and the source, provide a link to the Creative Commons license, and indicate if changes were made.

The online version of the original article can be found under doi:10.1007/S12182-016-0081-x.

Yong-Tu Liang

liangyt21st@163.com

1 Beijing Key Laboratory of Urban Oil and Gas Distribution Technology, China University of Petroleum, Beijing 102249, China

2 CNPC Trans-Asia Gas Pipeline Company Ltd., Beijing 100007, China 


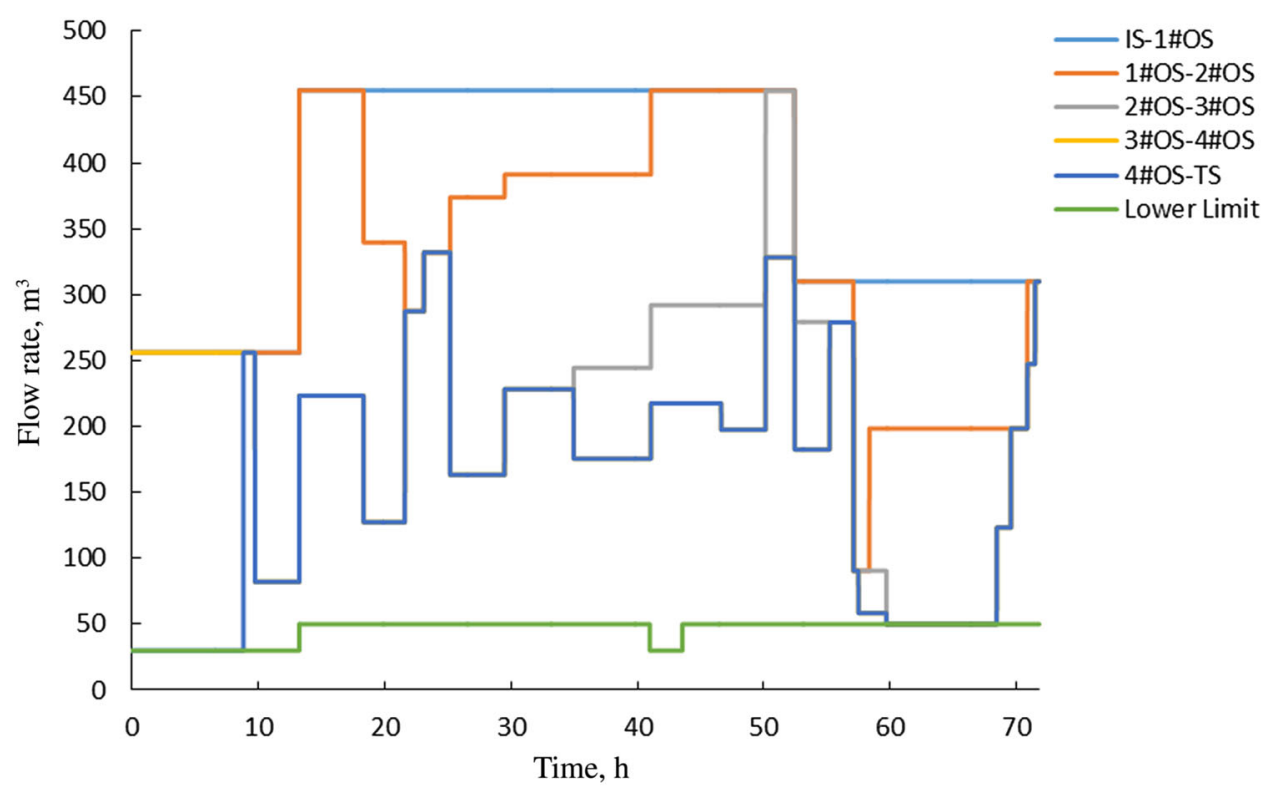

Fig. 4 Example one: flow rate in each pipeline segment and its lower limit 